\title{
One patient with Sjogren's syndrome presenting schizophrenia-like symptoms
}

\author{
This article was published in the following Dove Press journal: \\ Neuropsychiatric Disease and Treatment \\ 22 March 2016 \\ Number of times this article has been viewed
}

\author{
Ching-En Lin ${ }^{1,2}$ \\ 'Department of Psychiatry, Taipei \\ Tzu-Chi Hospital, Buddhist Medical \\ Foundation, Taiwan, Republic of \\ China; ${ }^{2}$ School of Medicine, Tzu-Chi \\ University, Hualien, Taiwan, Republic \\ of China
}

\begin{abstract}
Comorbid depression in patients with Sjogren's syndrome has been reported frequently, while comorbid psychosis in subjects with Sjogren's syndrome has rarely been reported. Here we report a patient with Sjogren's syndrome who presented with schizophrenia-like symptoms such as persecutory delusions and auditory hallucinations in contrast to her previous psychiatric presentations, which only included depression and anxiety.
\end{abstract}

Keywords: mental illness, psychosis, Sjogren's syndrome, schizophrenia

\section{Introduction}

Sjogren's syndrome (SS) is a systemic autoimmune disease characterized by a chronic inflammation of lacrimal and salivary glands, which leads to loss of tears (keratoconjunctivitis) and saliva (xerostomia). ${ }^{1}$ It could be termed primary or secondary to another chronic inflammatory diseases (mainly rheumatoid arthritis, systemic lupus erythematosus, multiple sclerosis, or progressive systemic sclerosis). Higher rates of central nervous system (CNS) involvement than expected have been documented recently. ${ }^{2}$ Here, we report a case with primary SS who presented schizophrenia-like symptoms, which is a relative rare presentation.

\section{Case report}

A 41-year-old female with SS developed acute psychotic symptoms with evident auditory hallucinations and delusions of being possessed for 2 months. Traced back to her prior history, there were no other medical or surgical history, traumatic history, and substance-abuse history except for underlying SS comorbid with major depressive disorder treated with escitalopram $10 \mathrm{mg} / \mathrm{d}$. This case report was written retrospectively so informed consent was unable to be obtained and information was gained anonymously without ethical conflicts. The study protocols were approved by the Taipei Tzu Chi Hospital, Buddhist Tzu Chi Medical Foundation Institutional Review Board. Primary SS was diagnosed based on subjective symptoms of dry mouth and dry eyes for more than 3 months plus objective signs of salivary scintigraphy and autoantibodies to Ro (SS-A) and L (SS-B), showing severely impaired uptake of bilateral submandibular glands and markedly impaired uptake of bilateral parotid glands. Moreover, she had one prior psychotic episode 2 years ago, while laboratory data showed anti-Ro antibody (SS-A) and anti-La (SS-B) positive. The prior psychotic symptoms spontaneously were in full remission after methylprednisolone was administered. This time, she was admitted in the psychiatric ward first and treated with escitalopram $10 \mathrm{mg} / \mathrm{d}$ and risperidone titrated upward gradually to $4 \mathrm{mg} / \mathrm{d}$ within 2 weeks. Furthermore, she was also treated with immunosuppressant (hydroxychloroquine $200 \mathrm{mg}$ orally once
Correspondence: Ching-En Lin

Department of Psychiatry, Taipei Tzu-Chi Hospital, Buddhist Medical Foundation,

Taiwan, Republic of China

Email chingenlinaa@gmail.com
Neuropsychiatric Disease and Treatment 2016:12 661-663

(c) (1) \& ๑ 2016 Lin. This work is published and licensed by Dove Medical Press Limited. The full terms of this license are available at https://www.doverpess. com/terms.php cc. hereby accept the Terms. Non-commercial uses of the work are permitted without any further permision from Dove Medical Press Limited, provided the work is properly atrtibuted. For permision for commercial use of this work, please see paragraphs 4.2 and 5 of our Terms (htpps://www.dovepress. com/terms.php).

661
Dovepress

http://dx.doi.org/1 0.2147/NDT.S97753

.


a day) as usual. During admission, physical and neurological examinations showed no abnormality. Laboratory data for autoimmune disease revealed that antinuclear antibody was negative, whereas anti-Ro antibody (SS-A) and anti-La (SS-B) were positive. Electroencephalogram and magnetic resonance image showed no biological abnormality. Despite optimal dose and duration of risperidone administered, the patient's psychotic symptoms got worse. Therefore, we then consulted a rheumatologist, and methylprednisolone $500 \mathrm{mg}$ intravenous infusion once daily was suggested to be used for 3 days during initial 2 weeks admission. Dramatically, her psychotic symptoms were in remission totally within 3 days after methylprednisolone therapy completed. Risperdal dosage was even reduced to $2 \mathrm{mg} / \mathrm{d}$ before discharge. Escitalopram $10 \mathrm{mg} / \mathrm{d}$ and hydroxychloroquine $200 \mathrm{mg} / \mathrm{d}$ were kept for therapy. After discharge for 2 months, risperidone was even stopped totally. Finally, she was only treated with escitalopram and hydroxychloroquine without any antipsychotic agents. No further psychotic symptom recurrences were observed received during 6 months follow-up after discharge.

\section{Discussion}

Primary SS is a systemic autoimmune disease characterized by chronic inflammation and lymphocytic infiltration of exocrine lacrimal and saliva glands, causing dry mouth (xerostomia) and dry eye (xerophthalmia). ${ }^{3}$ Other than affecting glandular organs, SS can also have CNS manifestations, including focal neurological deficits, diffuse cerebral involvement (ie, aseptic meningitis, vascular encephalopathy, and dementia), and psychiatric disorders, including schizophrenia-like psychosis, somatization, dementia, dissociation, mood disorders, anxiety disorders, and abnormal personality traits. ${ }^{4}$ The prevalence of primary SS varies between $0.5 \%$ and $1 \%$ of the general population with female predominance, and it can occur at any age, especially after age 40 years. ${ }^{3,5}$

Primary SS generally does not affect the brain, and so most clinicians fail to consider CNS involvement in their differential diagnosis, ${ }^{6}$ which results in delayed diagnosis. The prevalence of CNS disease in SS is a controversial topic. The reasons for a huge variability in the reported prevalence of CNS involvement can be explained in four parts. First, no consensus on the definition of CNS involvement was reached. Some authors included psychiatric diseases, but some did not. Second, the diagnostic criteria used for primary SS were not uniform. Third, some studies included patients with secondary SS, some of whom may have lupus with CNS disease. Finally, confounding factors included cerebrovascular disease such as diabetes, hypertension, and hyperlipidemia or factors that may be associated with psychiatric disease. Therefore, the association of schizophrenia-like symptoms and primary SS is still unclear. Till date, one Taiwanese nationwide population-based study revealed that primary SS patients had higher psychotic disorder comorbidity than patients without primary $\mathrm{SS}^{7}$ but this was not shown in another Taiwanese study. ${ }^{8}$ The discrepancy between the two studies may stem from the difference in study design (retrospective cohort study versus cross-sectional study) and psychiatric diagnosis (ICD-9-CM codes for schizophrenia (295) versus the Elixhauser Comorbidity Index for psychosis).

The patient failed to show treatment response to optimal dose and duration of risperidone until methylprednisolone administration, which may indicate possible base for CNS involvement: immune-mediated inflammatory vascular disease and direct infiltration of cerebral tissue with chronic inflammation. ${ }^{9}$ This may partially explain why risperidone alone did not work until methylprednisolone administration. Moreover, the titer of SS-A antibody in serum is associated with psychiatric disorders, ${ }^{4}$ and patients with SS-A-positive antibody have certain clinical, neurodiagnostic, and immunopathological features distinguishing them from patients without these antibodies. ${ }^{10}$ This supports the idea that neuroimmune mechanisms may play a role in the etiology and pathophysiology of psychotic disorders, including antibodies to N-methyl-d-aspartate receptors, $\gamma$-aminobutyric acid A receptors, and voltage-gated ion channels, all of which have previously been linked to the pathophysiology of psychotic disorders such as schizophrenia. ${ }^{11,12}$ The SS-CNS patient suffered recurrent schizophrenia-like symptoms in contrast with her usual psychiatric presentation, major depression, indicating that one patient may present different psychiatric disorders in different phases of SS. On the basis of this case report, CNS-SS should be ruled out when patients display different or treatment-refractory psychiatric symptoms, since the incidence of psychiatric and/or cognitive impairment may be as high as $80 \%$ in patients with CNS-SS. ${ }^{4}$ In addition, serum autoantibody titers should be checked to confirm if SS is in active phase and methylprednisolone is to be used.

\section{Disclosure}

The author reports no conflicts of interest in this work.

\section{References}

1. Sjögren H. Zur kenntnis der keratoconjunctivitis SICCA II. Acta Ophthalmol. 1935;13(1-2):1-39.

2. Mauch E, Völk C, Kratzsch G, et al. Neurological and neuropsychiatric dysfunction in primary Sjögren's syndrome. Acta Neurol Scand. 1994;89(1):31-35.

3. Fox RI. Sjögren's syndrome. Lancet. 2005;366(9482):321-331. 
4. Cox PD, Hales RE. CNS Sjögren's syndrome. J Neuropsychiatry Clin Neurosci. 1999;11(2):241-247.

5. Mavragani CP, Fragoulis GE, Tzioufas AG, Moutsopoulos HM. Sjögren's syndrome. Encyclopedia of Medical Immunology. New York, NY: Springer; 2014:1069-1075.

6. Moutsopoulos HM, Youinou P. New developments in Sjogren's syndrome. Curr Opin Rheumatol. 1991;3(5):815-822.

7. Shen C-C, Yang AC, Kuo BI-T, Tsai S-J. Risk of psychiatric disorders following primary Sjögren syndrome: a nationwide population-based retrospective cohort study. J Rheumatol. 2015;42(7):1203-1208.

8. Kang J-H, Lin H-C. Comorbidities in patients with primary Sjögren's syndrome: a registry-based case-control study. J Rheumatol. 2010;37(6): 1188-1194.
9. Mataró M, Domingo Escudero M, Ariza M, et al. Magnetic resonance abnormalities associated with cognitive dysfunction in primary Sjögren syndrome. J Neurol. 2003;250(9):1070-1076.

10. Spezialetti R, Bluestein HG, Peter JB, Alexander EL. Neuropsychiatric disease in Sjögren's syndrome: anti-ribosomal $\mathrm{P}$ and anti-neuronal antibodies. Am J Med. 1993;95(2):153-160.

11. Benros ME, Eaton WW, Mortensen PB. The epidemiologic evidence linking autoimmune diseases and psychosis. Biol Psychiatry. 2014; 75(4):300-306.

12. Deakin J, Lennox BR, Zandi MS. Antibodies to the N-methyl-D-aspartate receptor and other synaptic proteins in psychosis. Biol Psychiatry. 2014; 75(4):284-291.
Neuropsychiatric Disease and Treatment

\section{Publish your work in this journal}

Neuropsychiatric Disease and Treatment is an international, peerreviewed journal of clinical therapeutics and pharmacology focusing on concise rapid reporting of clinical or pre-clinical studies on a range of neuropsychiatric and neurological disorders. This journal is indexed on PubMed Central, the 'PsycINFO' database and CAS,

\section{Dovepress}

and is the official journal of The International Neuropsychiatric Association (INA). The manuscript management system is completely online and includes a very quick and fair peer-review system, which is all easy to use. Visit http://www.dovepress.com/testimonials.php to read real quotes from published authors.

Submit your manuscript here: http://www.dovepress.com/neuropsychiatric-disease-and-treatment-journal 